\title{
Second generation of AVTIS FMCW millimeter wave radars for mapping volcanic terrain
}

\author{
David G. Macfarlane *, Duncan A. Robertson \& Scott L. Cassidy \\ University of St Andrews, SUPA School of Physics \& Astronomy, \\ St Andrews, Fife KY16 9SS, Scotland
}

\begin{abstract}
The second generation AVTIS ground-based millimeter wave instruments designed for monitoring topography of volcanic lava domes are solid state $94 \mathrm{GHz}$ FMCW rastered, real beam radars operating at ranges of up to $\sim 7 \mathrm{~km}$ with a range resolution of $\sim 2.5 \mathrm{~m}$. Operating ten times faster than the prototype with reduced power consumption suitable for battery powered portable use as well as installation at a telemetered site under solar power, we examine their performance as tools for monitoring topography over time and report on the operational statistics both as a radar sensor and as a means of generating digital elevation maps.
\end{abstract}

Keywords: Radar, FMCW, Millimeter wave, DEM, Terrain

\section{INTRODUCTION}

Direct observations of active volcanoes are often severely restricted by environmental conditions and hazards which can prevent timely measurements of changing volcanic terrain during periods of elevated activity. Driven by the extrusion of viscous lava from depth, active lava domes can significantly alter their topography (on the scale of meters) in just a few hours following periods of activity (or inactivity) that can last months or even years. Lava extrusion can start, stop or change direction with little or no warning ${ }^{1}$ Monitoring topographic change of lava domes in the periods leading up to dangerous and destructive collapse events therefore requires routine and timely survey measurements to construct Digital Elevation Models (DEMs) of evolving volcanic topography in a dense time series record. This is essential if collapse precursor activity is to be recorded and understood with the end goal of refining and improving lava dome growth and collapse models that can then be used for hazard warning and prediction by local scientists. Round-the-clock monitoring of topography requires weather-independent remote sensing for which radar is an obvious choice. Radar observations of volcanoes are now routinely made using satellite based interferometric synthetic aperture radar (InSAR) to measure deformation ${ }^{2}$, but these data are captured over relatively long repeat survey intervals (typically tens of days ${ }^{3}$ ), too long to capture the temporal detail of lava dome activity. In addition, although small scale changes at the flanks of a lava dome can be recorded by InSAR, the long repeat survey time intervals and large surface height changes on the scale of meters per day mean that radar returns from the lava dome itself are usually decorrelated and thus changes on the dome cannot be measured ${ }^{4}$ using that technique.

Ground based (GB) radars can obtain dense time series, however relatively few have been used to monitor volcanoes. Some long range $\mathrm{C}$-band weather radars have been used to probe eruption plumes from fixed ${ }^{5}$ or mobile ${ }^{6}$ platforms. A few GB Doppler radars have also measured the velocity of rockfalls, ejecta and gas fluxes ${ }^{7,8}$. Probably the longest serving GB radar monitoring an active volcano is located at Stromboli where a permanent Ku-band InSAR installation named LISA has been used since 2002 to record millimeter scale deformations at a range of around $1 \mathrm{~km}$ over short (few minute) intervals ${ }^{9}$, but this radar does not record DEMs. Another interferometric real aperture radar designed to measure deformation, the Ku-band GAMMA portable radar interferometer (GPRI), has also been developed to measure deformation and movement for mining sites and glaciers ${ }^{10}$ but has yet to be successfully applied to volcanic terrain.

We developed the first All-weather Volcano Topography Imaging Sensor, AVTIS1, to provide portable means for the topographic survey of volcanic lava domes in virtually any weather condition ${ }^{11}$. The instrument was also used successfully to measure lava flows ${ }^{12}$ and lava dome growth ${ }^{13}$. However, AVTIS1 suffered from long acquisition times, low signal-to-noise ratio (SNR) at long ranges, and limited operational duration due to battery consumption ${ }^{14}$.

*dgm5@st-and.ac.uk; phone +44 1334 461608; www.st-and.ac.uk/ mmwave

Radar Sensor Technology XX, edited by Kenneth I. Ranney, Armin Doerry, Proc. of SPIE Vol. 9829 $982907 \cdot$ ? 2016 SPIE · CCC code: 0277-786X/16/\$18 · doi: 10.1117/12.2223039 


\section{AVTIS SECOND GENERATION DESIGN: HISTORY AND MOTIVATION}

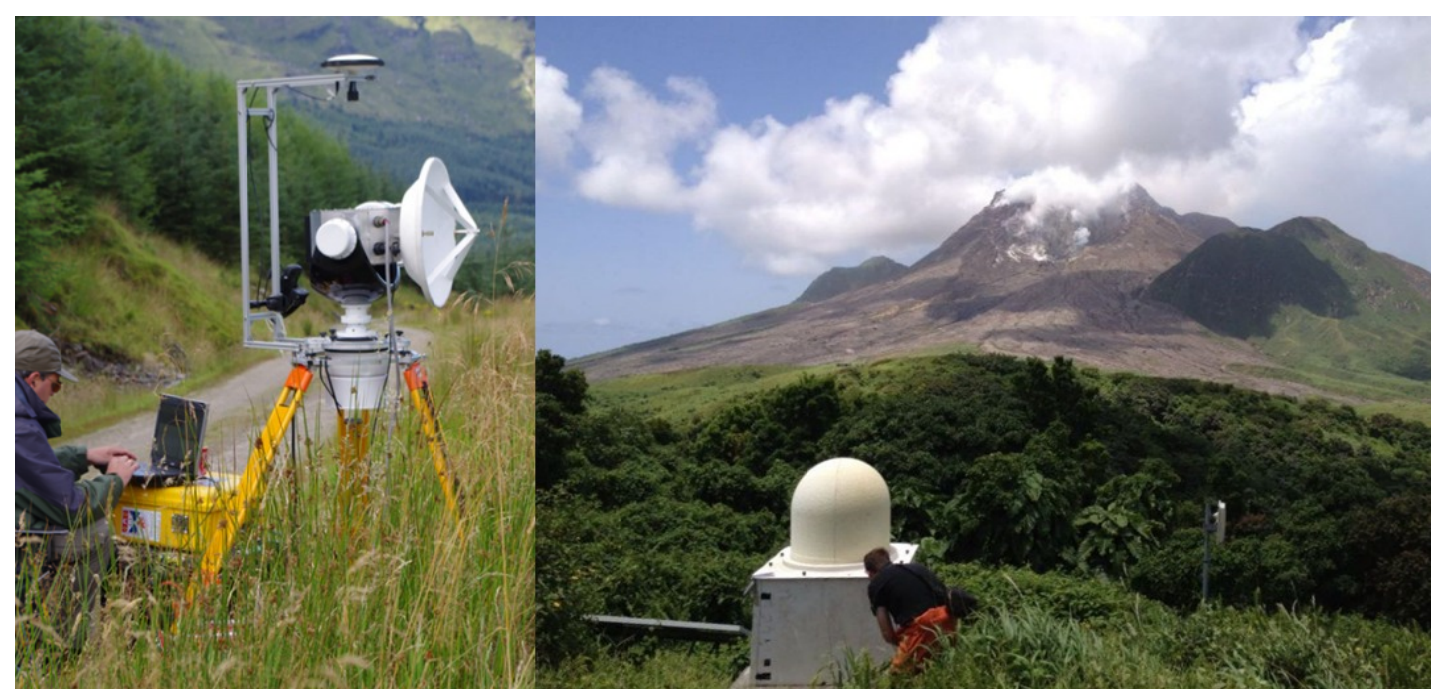

Fig. 1. AVTIS2 roving survey radar undergoing testing in Scotland, 2012 (left) and AVTIS3 under a radome at its remote telemetered installation at the Soufrière Hills Volcano (SHV), Montserrat, 2013 (right, photo Greg Scott). Both instruments are battery powered, gimbal mounted, rastered realbeam $94 \mathrm{GHz}$ FMCW radars designed to measure lava dome topography at a range of several $\mathrm{km}$.

In this paper we present our development of the improved, second generation instruments AVTIS2 and AVTIS3 (Fig. 1), compare their performance with AVTIS1, and present results for their range accuracy when acquiring DEMs. The original prototype instrument, AVTIS1, was a $94 \mathrm{GHz}$ dual-mode heterodyne radiometer and homodyne frequency modulated continuous wave (FMCW) radar that shared a common local oscillator derived from a multiplied $7.2 \mathrm{GHz}$ PMYTO $^{\dagger}$ source. Frequency multiplication $(\mathrm{x} 13)$ and power amplification were achieved using IMPATT $^{\ddagger}$ diode devices ${ }^{15}$. The battery powered sensor used a $30 \mathrm{~cm}$ Cassegrain antenna which was gimbal mounted on a surveyor's tripod. The $0.7^{\circ}$ pencil beam was rastered across the scene of interest to acquire range and radiometric temperature as a function of azimuth and elevation. As a proof of principle instrument, AVTIS1 was proven in the field at Soufrière Hills Volcano (SHV), Montserrat, and Arenal Volcano, Costa Rica between 2004 and 2006 obtaining DEMs and recording topographic changes of active lava domes and flows on a scale of $\mathrm{m} / \mathrm{day}^{13,14}$.

However, there were practical limitations with the deployment of AVTIS1 on Montserrat since remote locations with short range lines of sight (LOS) to the lava dome (1 to $3 \mathrm{~km}$ ) were only accessible by helicopter and access was often restricted by weather conditions. Safe locations with views of the dome and 24 hour access were available at much greater distances $(5$ to $7 \mathrm{~km}$ ) but these inevitably reduced the signal-to-noise ratio (SNR). The IMPATT devices employed produced excessive wideband amplitude noise which, combined with the finite transmit-receive leakage of the single-antenna design, resulted in a relatively high noise floor. To mitigate this, the FMCW chirp duration was kept long $(32 \mathrm{~ms})$ and it was necessary to average successive raster scans to produce DEM data of useful quality. This resulted in very long scan times (up to 8 hours) and deployments then became limited by the capacity of the system batteries.

To counter these limitations we designed a pair of new instruments which would have inherently lower noise floors and could thus use shorter chirps, enabling faster scan times, and reduced power consumption to extend battery operated duration and make autonomous operation feasible. AVTIS2 would be a brand new transportable instrument capable of long range $(7 \mathrm{~km})$, rapid capture of high quality data from multiple locations, and AVTIS3 would be an evolution of AVTIS1 into a fully autonomous unit operating unattended for up to 30 days at a time from relatively short ranges $(<4$ $\mathrm{km})$ providing data via wireless telemetry link. The two instruments were designed to have as much in common as possible to simplify development and provide redundancy. They have identical radar architectures, data acquisition hardware and control boxes, whilst the enclosures, antennas and gimbals differ due to the different range and deployment requirements. A comprehensive comparison of the system parameters between first and second generation of AVTIS instruments can be found in a previous publication ${ }^{16}$.

\footnotetext{
${ }^{\dagger}$ Permanent Magnet YIG Tuned Oscillator
}

`IMPact ionization Avalanche Transit-Time 


\section{AVTIS SECOND GENERATION DESIGN AIMS AND TECHNICAL ALTERATIONS}

The three main design aims for the second generation instruments were (i) to reduce the radar data acquisition time by a factor of ten (turning hours of scanning into minutes), (ii) to improve data quality such that averaging of successive scans was not required, and (iii) to minimize power consumption to maximize operational duration on batteries or allow autonomous operation using solar panels. Analysis of the well characterized AVTIS1 data ${ }^{14}$ suggested that the raw SNR from volcanic terrain required to be $>10 \mathrm{~dB}$ to avoid having to average multiple datasets. The first technical improvement over the prototype was therefore to reduce the radar noise figure floor which was achieved by replacing the IMPATT diode multiplier and amplifier with a x12 $\mathrm{MMIC}^{\S}$ multiplier of equivalent output power, driven by a $7.8 \mathrm{GHz}$ PMYTO oscillator. The much lower amplitude noise level of the MMIC multiplier reduced the radar noise floor by around $10 \mathrm{~dB}$ and consequently improved raw data quality.

AVTIS3 re-uses the antenna and gimbal from AVTIS1 but AVTIS2 is equipped with a new $45 \mathrm{~cm}$ Cassegrain antenna yielding $7 \mathrm{~dB}$ more signal gain and finer angular resolution to further improve performance at longer ranges. The narrower beamwidth and greater size and weight of the AVTIS2 antenna meant that a higher specification gimbal was selected. This has a yoke structure to support the payload and uses encoder-driven, closed-loop controlled stepper motors for superior pointing accuracy.

The AVTIS1 instrument was controlled by a standard consumer laptop which was sufficient for a prototype system. The new control box for AVTIS2/3 was designed to process, manage and store data on-site, interface with telemetry links and supervise power management, with low overall power consumption, all fitted in a portable, ruggedized enclosure. At its heart is a DC powered fanless PC with IP-rated keyboard mounted in a protective Peli case (Fig. 1)

A major problem with the AVTIS1 design was the coupling of electronic noise from the gimbal stepper motors into the receiver amplification chain leading to discrete bands of interference in the FMCW range spectra which had to be removed in post processing of the data. To alleviate this, the new design uses one power supply circuit for the radar sensor and a second, separate one for all other system components (controlling computer, gimbal, telemetry, etc.). This greatly reduces interference and improves signal fidelity. Also, the output signals in AVTIS1 were routed via several meters of cabling to a $500 \mathrm{kSa} / \mathrm{s}$ PCMCIA sampling card in the controlling laptop. For the second generation design, signals are sampled directly by a $50 \mathrm{MSa} / \mathrm{s}$ multifunction data acquisition module located inside the radar head and the umbilical connection to the control box is digital data over USB, greatly suppressing interference.

Based on work in St Andrews to develop real time 3D radar scanning for a separate project ${ }^{17}$ data processing rates were significantly improved in AVTIS2/3 by introduction of multithreaded processing (enabling simultaneous data capture, processing and storage), changing the FFT library to utilize the faster 'FFTW' library ${ }^{18}$ and the use of an optimizing C compiler. In AVTIS1 scanning speeds were slow since each individual FMCW range spectrum was captured for a fixed LOS with the gimbal stepped to its next position only after data capture and subsequent signal processing and data storage. In AVTIS2/3 the improvements described above allow data capture and processing to occur simultaneously as the antenna is being rastered across the scene with the timing of FMCW chirps and data capture both triggered by positional encoder signals from the gimbal.

For a typical AVTIS $2 / 3$ rastering speed of $2 \% \mathrm{~s}$ with triggering every $0.05^{\circ}$ there is an interval of $25 \mathrm{~ms}$ between the start of each chirp (or equivalently, each LOS). Chirp times have been reduced to around $0.65 \mathrm{~ms}$ (i.e. by a factor of $\sim 50$ ) and data capture and transfer (via USB) of each time series sample array to computer memory takes $\sim 8 \mathrm{~ms}$ leaving $\sim 15 \mathrm{~ms}$ as a buffer before the next LOS trigger. In practice data processing lags capture by only $\sim 1 \mathrm{~s}$ as the gimbal rasters in azimuth. The bulk of delay in scanning is taken up with the gimbal moving to the next elevation position.

The chirp generator for both generations of AVTIS radar uses a swept voltage to modulate the initial $\sim 7 \mathrm{GHz}$ PMYTO source. The AVTIS1 voltage waveform was produced using a custom built analogue circuit that was prone to temperature fluctuations which affected accuracy whereas AVTIS2/3 use a voltage ramp generated from a DDS-based waveform generator for a more stable and repeatable radar chirp.

\footnotetext{
${ }^{\S}$ Monolithic Microwave Integrated Circuit
} 


\section{AVTIS2 PERFORMANCE}

Initial field testing of AVTIS2 in Scotland consisted of scanning a local quarry at a distance of around 5 km (Fig. 2). These data show radar scans of the quarry several years apart acquired by AVTIS1 and AVTIS2 from approximately the same viewpoint. AVTIS3 was not tested at this location. Scanning times for these equivalent volumes were initially measured to have been reduced by a factor of around seven although the geometry of these scans was not optimal. In practice it was later found that large azimuthal sweeps were most efficient since stepping of elevations position accounts for less of the total time and the design aim of an improvement in scan times by a factor of 10 was achieved.
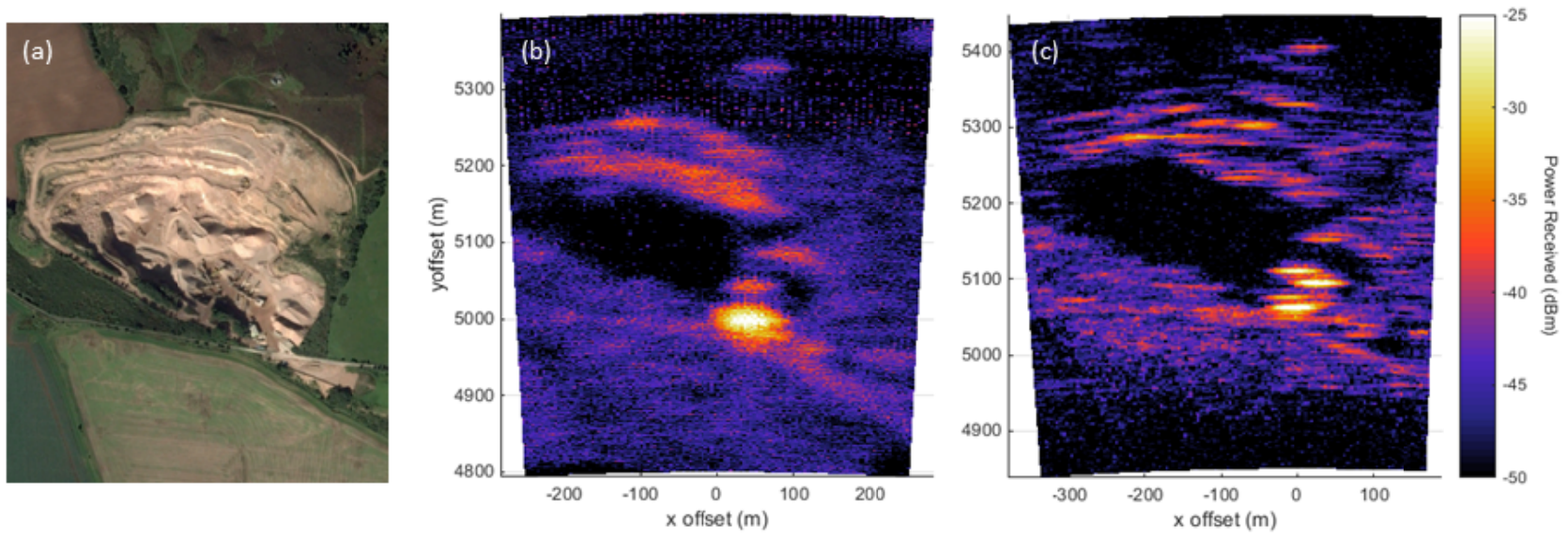

Fig. 2. (a) Balmullo Quarry, Fife, aerial image (c) Google maps, (b) AVTIS1 scan of quarry and (c) AVTIS2 scan of quarry. Both radar scans show a composite of maximum returns from several elevations. The brightest returns are from buildings inside the quarry.

Examining the quarry data shows that AVTIS2 clearly resolves finer features than AVTIS1, both in range and angle. The two data sets showed remarkably similar levels of received power and in fact highlight (at a qualitative level) that the improvements to lower the noise floor in the system design were sufficient to counteract the rise in noise floor associated with the increase in speed of radar chirps. AVTIS2 was then successfully used to survey the SHV in May of $2011^{19}$ where improvements in scan speed vastly increased the effective area that could be surveyed in practical field work timescales of a few hours (Fig. 3.). In fact, scan times were sufficiently improved such that both sides of the mountain could be surveyed in a single day, a situation that had not previously been achieved.
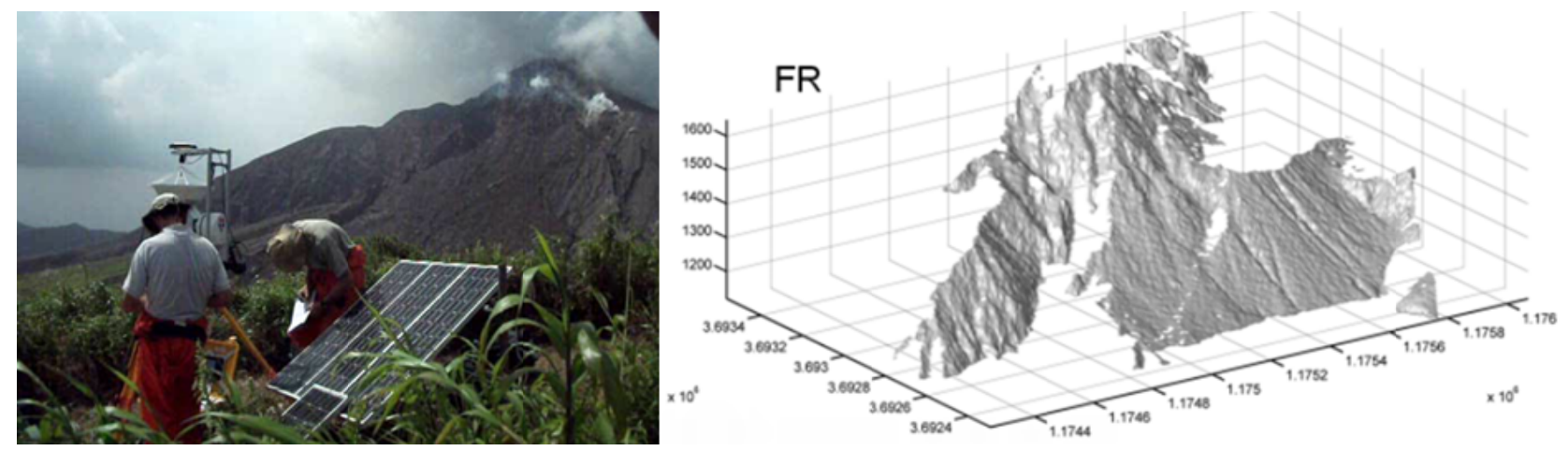

Fig. 3. AVTIS2 deployed in May of 2011 at SHV (left) with the associated digital elevation map survey data (right). 


\section{AVTIS3 PERFORMANCE}

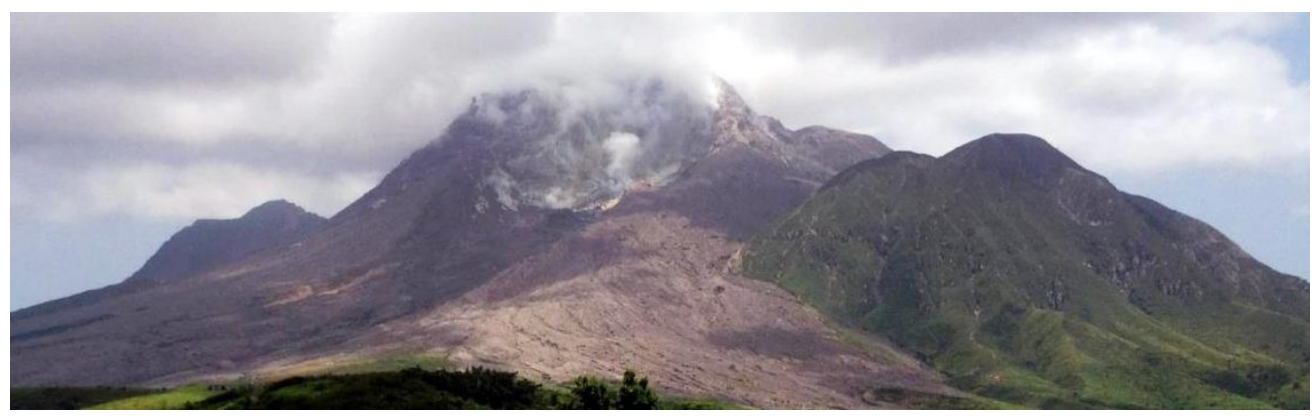

Fig. 4. View of SHV, Montserrat from the AVTIS3 remote site.

AVTIS3 was installed at SHV in May of 2011 with the view from the site (Fig. 1) as shown above (Fig. 4). The region of greatest interest was the collapse crater at the center of the photograph although the entire view is routinely scanned. The crater vents gas continuously and is generally covered in cloud. Terrain varies from vegetated and rocky slopes (on the right) to boulder field and ash deposits on the flanks of the mountain. Note that the left-most peak does not appear in the radar data since it was (intentionally) excluded from the data record as it was of lesser volcanological interest and by lying at further range significantly increased data storage requirements.

The prime aim of AVTIS3 is to record topographical change of the lava dome by measuring, constructing and comparing DEMs as a function of time. However, since the installation of AVTIS3 there has been no significant lava dome extrusion activity at SHV. Thus discussion of AVTIS3 performance here will consist of an examination of the repeatability of measurements of the static terrain. The angular view of the volcano from this viewpoint is large and is hence broken into sections to avoid wasting time scanning the sky. Each scan of the mountain takes $\sim 1$ hour covering an area equivalent to $20 \times 20^{\circ}$ at $0.05^{\circ}$ increments with a range resolution of $2.5 \mathrm{~m}$. Sample data for daytime and night time views are shown below (Fig. 5).

(a)

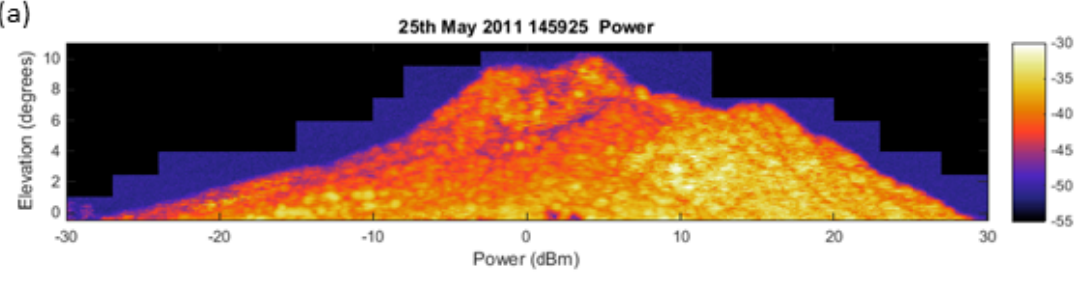

(c)

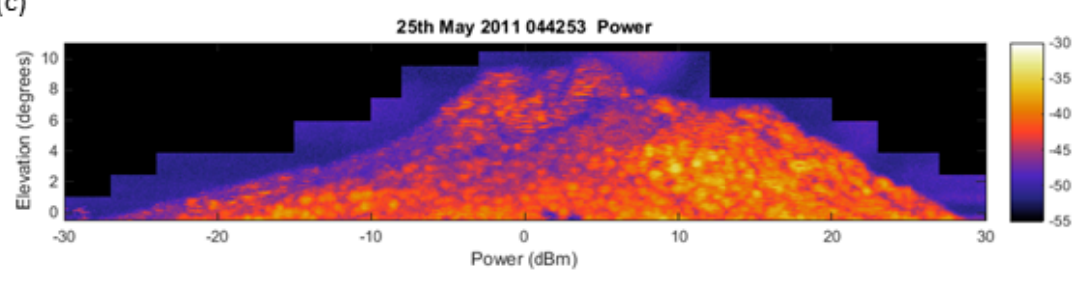

(b)

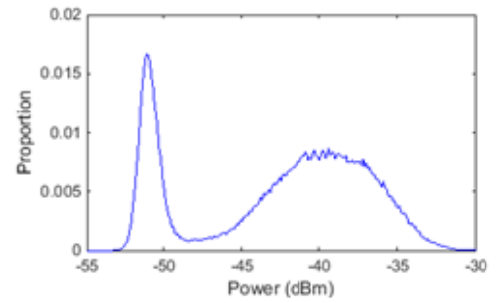

(d)

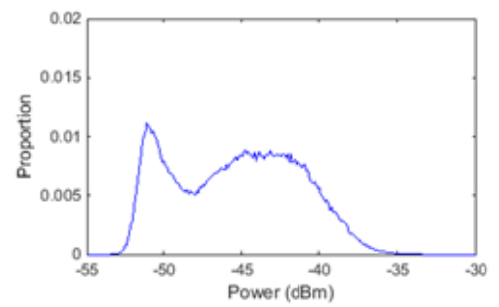

Fig. 5. AVTIS3 daytime received power image (a) and histogram (b), and night time received power image (c) and histogram (d).

Previous AVTIS DEM constructions of SHV automatically eliminated sky returns using a threshold of terrain radar cross section per unit area $\left(\sigma^{0}\right)$ which was calculated using assumptions for signal fading, averaging and general terrain inclination ${ }^{14}$. However those models were of relatively simple terrain and struggle with the variety of terrain seen across the AVTIS3 SHV scene in terms of topographical aspect to the radar point of view, terrain type (ash, rock, vegetation) and variations in localized weather conditions (gas, cloud, drizzle, rain and water vapour) all of which could affect limited regions within the scene. This made it difficult to make a robust automatic distinction between sky and terrain. 
As an example, the drop in received power from the terrain at night time shown above was reasonably uniform across the scene and was therefore most likely due to change in water vapour attenuation. The data shown above had a mode of $\sim 4$ $\mathrm{dB}$ increase in attenuation. The mean range to terrain in the scene is $\sim 3 \mathrm{~km}$ so the round trip mean is $\sim 6 \mathrm{~km}$. Excess attenuation is therefore around $0.67 \mathrm{~dB} / \mathrm{km}$ over and above the day time absorption rate. We have previously reported ${ }^{14} \mathrm{a}$ typical daytime attenuation rate for Montserrat of $1.3 \mathrm{~dB} / \mathrm{km}\left(22 \mathrm{~g} / \mathrm{m}^{3}\right.$ water vapour density $\left.{ }^{20}\right)$ so for this example there has been a modest increase to around $2 \mathrm{~dB} / \mathrm{km}\left(\sim 29 \mathrm{~g} / \mathrm{m}^{3}\right.$ water vapour density).

With such variability in conditions and large demand on telemetry and raw radar data storage (approximately 1 GB of raw data per scan every hour), data processing was carried out in real time at the AVTIS3 site computer with truncated radar spectra (containing the ranges of interest) telemetered to the observatory for storage. Data was stored as an average over each 24 hour period from May to September of 2011. The data shown in Fig. 6 illustrates the improvement in raw data quality that is achieved by simple averaging.
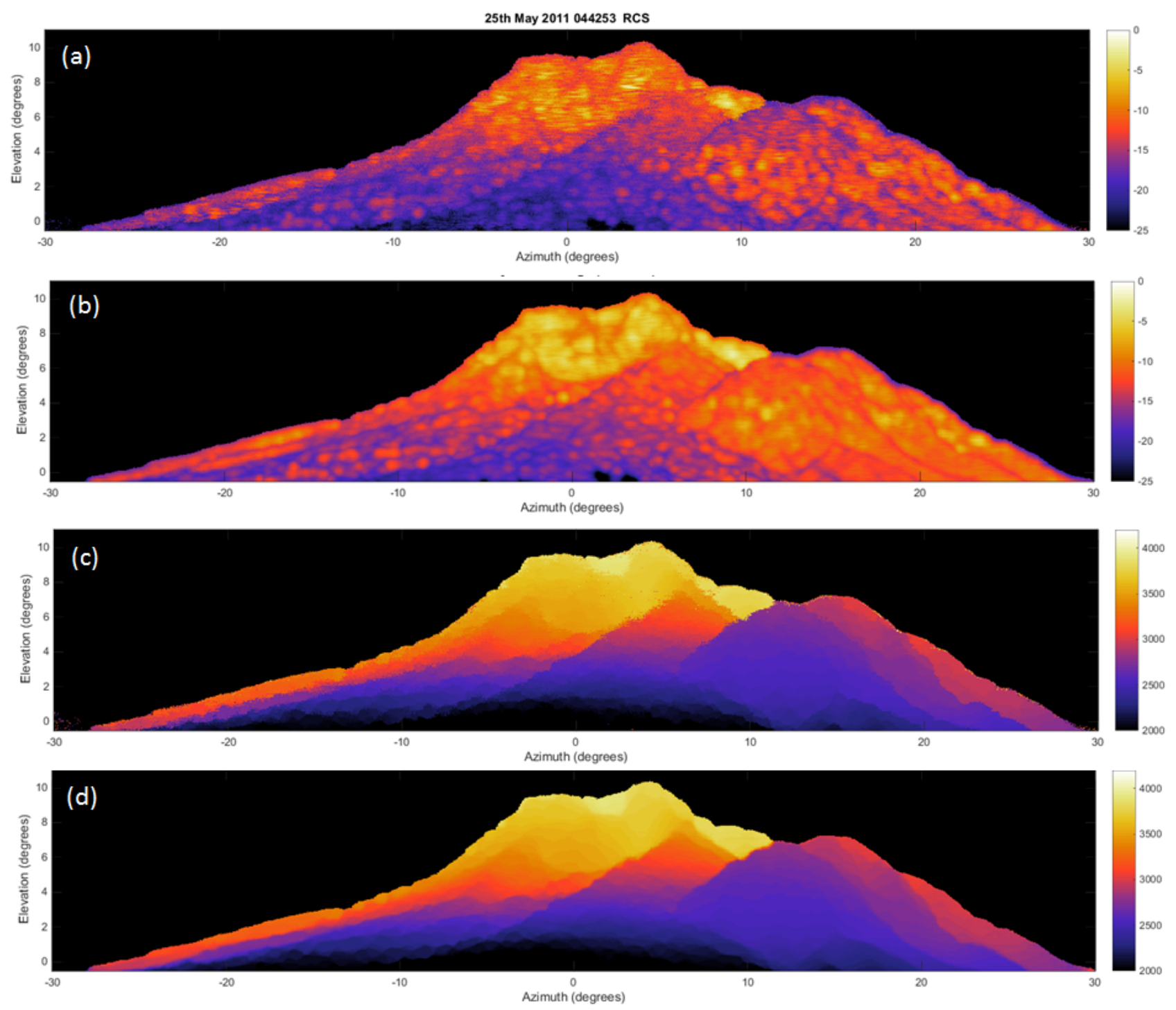

Fig. 6. (a) $\sigma^{0}$, single scan (b) $\sigma^{0}, 24$ hour average, (c) range, single scan and (d) range, 24 hour average. Note that these data have been masked to remove the sky based on the average profile of the mountain taken from several months of scans.

Repeated observation of the scene has allowed statistics on DEM construction to be evaluated. In terms of the actual range to terrain, the radar view can be plotted in terms of standard deviation in range (Fig.7) 


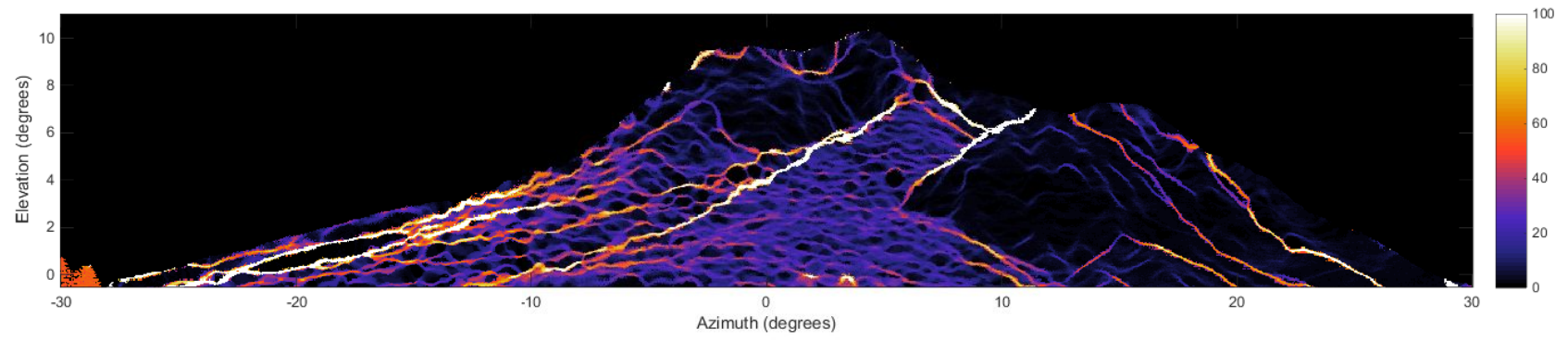

Fig. 7. Standard deviation in range over 20 days. The scale has been truncated at $100 \mathrm{~m}$ to show detail in the terrain.

Here the data shows that the range to surface is least accurate for occlusions or edges in terrain. Overall $25 \%$ of the scene has a standard deviation less than the range resolution of $2.5 \mathrm{~m}$. However, extreme values for standard deviation result from the difference in range between separated ridges and occlusions in the terrain. The algorithm that extracts range from the raw radar range spectra only returns one value and is insensitive to multiple strong returns at different distances contained with a single radar beam. Inclined terrain, such as the boulder strewn flanks of the volcano also show increased variability in range as the beam intercepts a larger extended footprint on the mountainside and can fluctuate between strong scatters contained therein. Conversely, steep faces present a more stable return and give low standard deviations in range (Fig. 8).

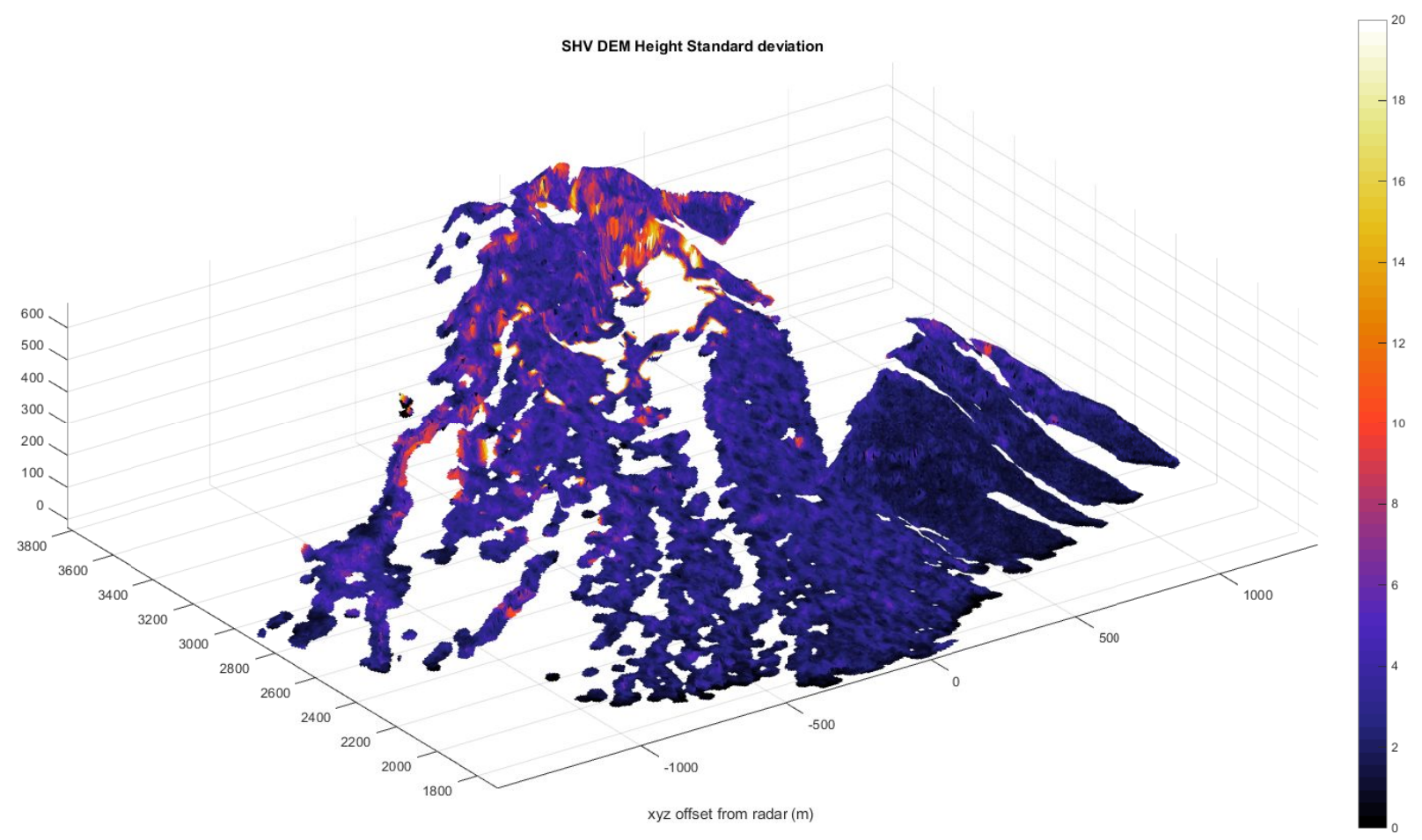

Fig. 8. AVTIS3 derived DEM of SHV showing standard deviation in DEM height (in meters) over 20 days.

Here we see that the steep vertical faces contained within the scene show the largest variability since elevation is not aligned with the radar LOS, i.e. a small error in range produces a large error in vertical height. Note that the edge occlusion effects in range are not evident in the DEM since variability in range merely corresponds to different regions of the DEM contained within the same LOS from the radar point of view. 


\section{DISCUSSION \& CONCLUSIONS}

The second generation of AVTIS instruments, AVTIS2 and AVTIS3, have been shown to meet their design goals of providing a faster round the clock means by which to record DEMs of the surface terrain of active volcanoes such as the SHV. Radar performance has been improved such that the speed of operation has increased by a factor of 10 allowing much larger areas to be scanned in a practical field survey. Changing topography has not yet been measured due to the recent volcanological inactivity at SHV. Range to surface topography has been shown to be reliable by averaging over 24 hours but DEM construction methods may have to be improved to better process steep faces in the terrain. In practice this could be achieved by scanning smaller areas of interest more often to improve averaging. During an actual eruption the height of the lava dome can change on a scale of several meters per day and we therefore expect that such changes would be detectable by the AVTIS instruments.

\section{ACKNOWLEDGEMENTS}

We wish to thank the UK Natural Environment Research Council for funding under grant NE/E015352/1. We extend a particularly big thank you to all the members of the Montserrat Volcano Observatory, past and present that have lent their invaluable assistance, expertise and time on the AVTIS projects. We are especially indebted to Dr Adam Stinton and Mr Pyiko Williams for their efforts to maintain the AVTIS3 installation since 2011

\section{REFERENCES}

[1] S.C. Loughlin, R. Luckett, G. Ryan, T. Christopher, V. Hards, S. De Angelis, L. Jones and M. Strutt, "An overview of lava dome evolution, dome collapse and cyclicity at Soufrière Hills Volcano, Montserrat, 20052007”, Geophys. Res. Lett., 37, L00E16, (2010), doi:10.1029/2010GL042547.

[2] Z. Lu and D. Dzurisin, InSAR Imaging of Aleutian Volcanoes: Monitoring a Volcanic Arc from Space, Springer Praxis Books, Geophysical Sciences, (2014), pp 87-345

[3] S. K. Ebmeier, J. Biggs, T. A. Mather and F. Amelung, "Applicability of InSAR to tropical volcanoes: insights from Central America", Geol. Soc., London, Special Publications, 380, Remote-sensing of volcanoes and volcanic processes: Integrating observation and modelling, (2013), doi:10.1144/SP380.2.

[4] G. Wadge, G.S. Mattioli and R.A. Herd, "Ground deformation at Soufrière Hills Volcano, Montserrat during 1998-2000 measured by radar interferometry and GPS", J.Volc. Geothermal Res., 152, 1-2, pp 157-173, April 2006, doi:10.1016/j.jvolgeores.2005.11.007

[5] L. Mereu, F.S. Marzano, M. Montopoli and C. Bonadonna, "Retrieval of Tephra Size Spectra and Mass Flow Rate From C-Band Radar During the 2010 Eyjafjallajökull Eruption, Iceland", IEEE Trans. Geo. Rem. Sens. 53, 10, pp 5644, doi:10.1109/TGRS.2015.2427032

[6] D.J. Schneider and R.P. Hoblitt, "Doppler weather radar observations of the 2009 eruption of Redoubt Volcano, Alaska", J.Volc. Geoth. Res., 259, pp 133-144, 2013, doi:10.1016/j.jvolgeores.2012.11.004

[7] F. Donnadieu, P. Frevilled, C. Hervierd, M. Coltellie, S. Scolloe, M. Prestifilippoe, S. Valadea, S. Rivetd and P. Cacault, "Near-source Doppler radar monitoring of tephra plumes at Etna", J. Volcanol.Geothermal Res., vol. 312, pp. 26-39, Feb. 2016. doi:10.1016/j.jvolgeores.2016.01.009

[8] M. Vöge and M. Hort, "Automatic classification of dome instabilities based on Doppler radar measurements at Merapi volcano, Indonesia: Part I", Geophys. J. Int. (2008) 172 (3): 1188-1206. doi: 10.1111/j.1365246X.2007.03605.x

[9] F. Di Traglia et al., "The ground-based InSAR monitoring system at Stromboli volcano: Linking changes in displacement rate and intensity of persistent volcanic activity", Bull. Volc., 76, pp 1-18, 2014, doi: $10.1007 / \mathrm{s} 00445-013-0786-2$

[10] Strozzi, C. Werner, A. Wiesmann and U. Wegmuller, "Topography mapping with a portable real-aperture radar interferometer," IEEE Geosci. Remote Sens. Lett., vol. 9, no. 2, pp. 277-281, Mar. 2012.

[11] G. Wadge, D. G. Macfarlane, D. A. Robertson, A. J. Hale, H. Pinkerton, R. V. Burrell, G. E. Norton, and M. R. James, "AVTIS: A novel millimetre wave ground based instrument for volcano remote sensing," J. Volcanol.Geothermal Res., vol. 146, no. 4, pp. 307-318, Sep. 2005.

[12]D.G Macfarlane, G. Wadge, D.A. Robertson, M.R. James and H. Pinkerton, "Use of a portable topographic mapping millimetre wave radar to an active lava flow", Geophys. Res. Lett., 33, L03301, (2006) doi: 10.1029/2005GL025005 
[13] G. Wadge et al,"Lava dome growth and mass wasting measured by a time series of ground-based radar and seismicity observations", J. Geophys. Res., 113, B08210, 2008, doi: 10.1029/2007JB005466

[14] Macfarlane, D.G., Odbert, H.M., Robertson, D.A., James, M.R., Pinkerton, H., and Wadge, G.,"Topographic and Thermal Mapping of Volcanic Terrain Using the AVTIS Ground-Based 94-GHz Dual-Mode Radar/Radiometric Imager," IEEE Trans. Geosci. Remote Sens., 51 (1) Part 2, 455-472, (2013); doi:10.1109/TGRS.2012.2202667

[15]D. A. Robertson and D. G. Macfarlane, "A $94 \mathrm{GHz}$ dual-mode imaging radarometer for remote sensing", Proc. SPIE, 6211, Passive Millimeter-Wave Imaging Technology IX, 621102, 5 May 2006, doi: 10.1117/12.669668

[16] Macfarlane, D.G., Robertson, D.A., Cassidy S.L., Odbert, H.M., James,M.R, Pinkerton, H and Wadge,G., "Passive and active imaging at $94 \mathrm{GHz}$ for environmental remote sensing", Proc. SPIE 8715, Passive and Active Millimeter-Wave Imaging XVI, 87150L (May 31, 2013); doi:10.1117/12.2015730

[17] Robertson, D.A., Marsh, P.N., Bolton, D.R., Middleton, R.J.C., Hunter, R.I., Speirs, P.J., Macfarlane, D.G., Cassidy, S.L., and Smith, G.M., "340 GHz 3D radar imaging test bed with $10 \mathrm{~Hz}$ frame rate.", Proc. SPIE 8362, Passive and Active Millimeter-Wave Imaging XV, 836206, (2012).

[18] http://www.fftw.org/

[19] Wadge, G., Macfarlane, D.G, Odbert, H.M., Stinton, A., Robertson, D.A., James, M.R., and Pinkerton, H., "AVTIS observations of lava dome growth at Soufrière Hills Volcano, Montserrat: 2004-2011," An overview of the eruption of Soufriere Hills Volcano, Montserrat from 2000-2010. In, Wadge, G., Robertson, R., Voight, B. (eds.). Geological Society, London, Memoirs 2014, v. 39, p. 229-240, doi: 10.1144/M39.13

[20] ITU P.676 : Attenuation by atmospheric gases, https://www.itu.int/rec/R-REC-P.676-3-199708-S/en 